\title{
O discurso político-ideológico do "desenvolvimento sustentável”: uma crítica à luz da epistemologia da linguagem e da teoria discursiva de Michel Foucault
}

\author{
The ideological-political discourse on "sustainable development": a criticism \\ by the light of the language epistemology and the discourse theory of Michel \\ Foucault
}

\author{
Elda Coelho de Azevedo Bussinguer \\ Isabela de Deus Cordeiro** \\ Shayene Machado Salles ${ }^{* *+}$
}

\section{Resumo}

Propõe-se analisar a expressão "desenvolvimento sustentável" a partir da teoria discursiva de Michel Foucault presente na obra "A ordem do discurso", tendo em vista uma crítica à mensagem por ela traduzida e consequentemente ao seu conteúdo político-ideológico. Nesse contexto, a transição epistêmica vivenciada pela filosofia linguagem, da Semiologia à Ordem do discurso, é apresentada como caminho para o avanço das reflexões suscitadas pelo estudo, especialmente em função da articulação de conceitos como o de "significado contextual", proveniente da epistemologia, com fundamentos da teoria discursiva de Foucault. A elucidação dos procedimentos de exclusão da "interdição da palavra" e da "vontade de verdade" permitem exemplificadamente constatar relações de poder intrínsecas à linguagem que contribuem para a compreensão de que a expressão "desenvolvimento sustentável" serve à manutenção dos ideais de sobrevivência da ordem capitalista globalizada, estabelecendo um contínuo e permanente diálogo com a realidade, por meio do qual sinaliza e alimenta, social e institucionalmente, a subordinação da proteção ambiental ao desenvolvimento econômico.

Palavras-chave: Linguagem. Filosofia. Discurso. Princípio do Desenvolvimento Sustentável.

\section{Abstract}

The article intends to analyze the expression "sustainable development", from the discourse theory of Michel Foucault in his work "The order of the Discourse", viewing a criticism to its message and, consequently, to its ideological-political content. In this context, the epistemic transition, experienced by language philosophy, from Semiology to the Order of the Discourse, is presented as a path for the advance of the thoughts aroused by the study, specially, in function of the articulation of concepts such as "contextual meaning!, coming from epistemology, with fundaments of Foucault's discourse theory. The elucidation of the procedures of exclusion of the "word interdiction" and of the "will of truth", exemplified, allows to ascertain relations of power intrinsic to the language which contribute to the understanding that the expression "sustainable development" serves to the maintenance of the ideas of survival of the global capitalist order, establishing a continuum and permanent dialogue with reality through which symbolizes and feeds, social and institutionally, the subordinations of the environmental protection to the economic development.

Keywords: Language. Philosophy. Discourse. Principle of Sustainable Development.

Doutora em Bioética pela Universidade de Brasília (Unb); Livre-docente pela Universidade Federal do Estado do Rio de Janeiro (Unirio); Mestre em Direitos e Garantias Fundamentais pela Faculdade de Direito de Vitória (FDV); Coordenadora e professora do Programa de Pós-Graduação em Direitos e Garantias Fundamentais da Faculdade de Direito de Vitória (FDV); Coordenadora de Pesquisa da FDV; Coordenadora do Grupo de Estudos, Pesquisa e Extensão em Políticas Públicas, Direito à saúde e Bioética (BIOGEPE); Professora associada aposentada da Universidade Federal do Espírito Santo (Ufes). Vitória - ES - Brasil. E-mail: elda.cab@gmail.com.

Mestre pelo Programa de Pós-Graduação em Direitos e Garantias Fundamentais da Faculdade de Direito de Vitória (FDV); Especialista em Direito Urbanístico pela Fundação Escola do Ministério Público do Rio Grande do Sul; Especialista em Direito Constitucional pela Universidade Federal do Espírito Santo; Membro do Grupo de Estudos, Pesquisa e Extensão em Políticas Públicas, Direito à Saúde e Bioética (BIOGEPE); Promotora de Justiça do Ministério Público do Estado do Espírito Santo. Vitória - ES- Brasil. E-mail: isabeladedeus@hotmail.com.

** Mestre pelo Programa de Pós-Graduação em Direitos e Garantias Fundamentais da Faculdade de Direito de Vitória (FDV); Membro do Grupo de Estudos, Pesquisa e Extensão em Políticas Públicas, Direito à Saúde e Bioética (BIOGEPE). Coordenadora do Centro Especializado em Direitos Humanos da Prefeitura Municipal de Vitória. Advogada. Vitória - ES- Brasil. E-mail: shayenemachado@gmail.com. 


\section{Introdução}

A segregação do homem em relação à natureza e à concorrência com ela estabelecida por meio do sistema capitalista de produção, fez substituir o movimento humanista, segundo o qual o homem e a natureza são um, pelo movimento da produção e consumo, e por esse movimento as coisas simplesmente são postas e sobre elas há um espaço limitado de criticidade.

A sociedade liberal e a atual sociedade neoliberal são frutos desse movimento e, como tal, utilizamse de linguagens especificamente criadas para a reprodução daquilo que compõe o vértice do movimento de produção e consumo, qual seja, a segregação do homem em relação à natureza e consequente exploração como forma de manutenção da vida.

Esse contexto tem como um de seus aspectos contributos a questão da linguagem e como, a partir do controle discursivo, pode ela representar a manutenção do sistema posto e pressuposto. É a partir desse contexto que se propõe a problemática a envolver a expressão "desenvolvimento sustentável", cuja criação opera a própria reprodução do sistema produtivo, representando chances bastante limitadas de rompimento do estado de segregação estabelecido a partir do movimento de produção e consumo, além de nenhuma alternativa que reconduza o homem a uma relação de integridade com a natureza.

Afirma-se, com isso, que as discussões acerca da constituição do campo internacional da expressão "desenvolvimento sustentável" se deram em um contexto no qual foi cunhada como uma alternativa ao modelo de desenvolvimento posto (BRÜSEKE, 1994) representando, contudo, a sua própria manutenção.

Na década de 70, por meio dos estudos apresentados por Dennis L. Meadows acerca dos "limites do crescimento", bem como dos debates oriundos da Conferência de Estocolmo (1972), a questão do "desenvolvimento sustentável" foi suscitada diante da necessidade de refletir acerca dos danos ambientais nefastos resultantes da degradação progressiva que, desde a década de 60 , já se alarmava (BRÜSEKE, 1994).

Este estudo propõe críticas à expressão "desenvolvimento sustentável" que transcendem a análise das justificativas apresentadas quando do seu nascimento durante a elaboração do Relatório da Comissão Mundial sobre Meio Ambiente e Desenvolvimento Sustentável, também conhecido como Relatório de Brundtland.

Do ponto de vista metodológico, trata-se de pesquisa qualitativa, cuja execução se pautou numa abordagem dialética que se propõe a suscitar reflexões mais do que oferecer respostas às questões, isto é, ao processo, em contínuo movimento, das relações de interesse que constituem o uso e a aplicação da expressão "desenvolvimento sustentável".

Para tanto, tendo em vista uma análise da teoria discursiva de Michel Foucault na obra "A ordem do discurso", promover-se-á uma crítica da expressão a partir do que está por trás da mesma, ou seja, não do que ela apresenta como significado de base, mas muito mais a partir da mensagem por ela traduzida, da visão e concepção de mundo que a orienta e que propiciará a compreensão em torno de seu conteúdo político-ideológico.

Nesse sentido, a opção por essa obra de Foucault está relacionada à condição do autor haver se debruçado sobre as estratégias de controle discursivo, mas não só isso. Também em função de sua análise sobre os fatores e contingências que sinalizam os espaços e as disputas de poder, as formas e os mecanismos voltados para sua afirmação e perenização, inclusive assumindo condições veladas ou discretas por meio de linguagens capazes de criar discursos de "vontade de verdade".

A partir disso, pretende-se responder ao seguinte questionamento: Que contribuições a teoria discursiva de Michel Foucault oferece para a compreensão crítica do discurso político-ideológico que comporta a expressão "desenvolvimento sustentável"? 
Dito isso, convém esclarecer o percurso teórico que será desenvolvido nesta pesquisa: No primeiro tópico, serão apresentadas algumas considerações introdutórias indispensáveis para a apresentação da transição epistêmica da linguagem tendo em vista a identificação da sua contribuição esta para a questão-problema proposta neste estudo. O segundo tópico apresenta os fundamentos da teoria discursiva de Foucault, especialmente em função das relações de poder intrínsecas à linguagem. E, finalmente, a aplicação teórica do discurso de Foucault, visando elucidar o caráter político-ideológico da expressão "desenvolvimento sustentável", à luz da permanente subordinação da proteção ambiental ao desenvolvimento econômico.

\section{Da transição epistêmica: da semiologia à "ordem do discurso" de Michel Foucault}

A transição epistêmica vivenciada pela filosofia da linguagem durante os séculos XVII a XX é o ponto de partida para a identificação da epistemologia que orienta o recorte metodológico proposto neste breve estudo. Muito embora ela não seja o objeto central de interesse, representa de fato um caminho necessário à compreensão de como a linguagem atualmente é entendida e de como, a partir de um giro linguístico, vem sendo ela utilizada nas estratégias de manipulação, exclusão e exercício do poder.

No período mencionado, os reflexos práticos do que se denomina "transição epistêmica" puderam ser percebidos, tanto por meio da alteração do modo de se compreender o mundo (a partir do movimento da ciência) quanto por meio do trato científico dispensado à linguagem, sendo esse o foco do artigo.

É possível afirmar, nessa perspectiva, que os primeiros estudos da linguística pautaram-se nas discussões acerca da linguagem extraída do conhecimento científico dos signos, "[...] da tentativa de se considerar os signos como objeto específico de um conhecimento científico", construindo um edifício intelectual rigidamente sustentado por teóricos como Ferdinand de Saussure, que aos estudos desenvolvidos nominou "semiologia" (WARAT, 1995, p. 11), e Wittgenstein (1979, p. XX), a partir da perspectiva "logicista" da linguagem.

A semiologia proposta por Saussure, cuja "[...] preocupação metodológica vertebral é a determinação dos critérios que permitem a autonomia e a pureza de uma ciência dos signos", promoveu uma análise dos "signos verbais", identificando elementos invariáveis que traduzissem uma "teoria geral dos signos" (WARAT, 1995, p. 12; PETERS, 2000, p. 20-21). Assim é que a "[...] linguística, para Saussure, tem um papel privilegiado, pois apenas mediante suas categorias analíticas torna-se possível a constituição da semiologia." (WARAT, 1995, p. 12).

O autor apresenta uma perspectiva analítica da linguagem pautada no rigor linguístico exegético, incorporado por empiristas e intelectualistas que "[...] se preocupavam em 'purificar' a linguagem [...]" a fim de que ela servisse "[...] docilmente às representações conceituais" (CHAUÍ, 1999, p. 143).

Wittgenstein (1979, p. XIV; p. XX), influenciado por Sausurre, trabalhou na perspectiva inicial da linguagem como correspondência entre a figura e o que é afigurado, em abordagem conhecida como "teoria da figuração". Mesmo após a sua morte, momento em que foi publicada a obra "Investigações Filosóficas", compondo o segundo Wittgenstein, cuidou de limitar a linguagem à sua análise desprovida dos aspectos metafísicos, atribuindo esses últimos à filosofia, e não à linguagem.

É importante registrar que, para além da crítica ao purismo instrumental dos empiristas, a teoria de Saussure preocupou-se com a relação entre o signo, o usuário e o contexto e, assim como Wittgenstein (1979, p. XX), identificou o caráter eminentemente prático da linguagem, traduzindo diversas "formas de vida" e reconhecendo "um conjunto de jogos de linguagem". A linguagem, antes concebida como um ato de conhecimento, passou a ser objeto de um estudo mais acurado, tendo em vista a falta de univocidade e a constatação de que o sentido das palavras depende do contexto e dos usuários.

Assim, se na modernidade a verdade era racionalmente associada à correspondência com a realidade, o que Saussure vai dizer é que a linguagem se opera de forma reflexiva, por diversos sistemas 
de crenças e valores, pondo de lado a compreensão de que a verdade será alcançada pelo desvelar da coisa, mesmo porque esse não será igual para todos os sujeitos.

Nesse sentido, o signo linguístico é reflexivo e se opera mentalmente: primeiro, a coisa é mentalmente idealizada (imagem acústica), e depois emitida, sendo que o modo de captação dos signos linguísticos de cada sujeito será diferente (PETERS, 2000, p. 35-37).

Essa perspectiva filosófica da linguagem enquanto constitutiva dos objetos inseridos em seus respectivos contextos, e não enquanto um instrumento imanente utilizado para nominar objetos, não significou uma ruptura com "[...] os imperativos da sistematicidade". Pelo contrário, a semiologia, assim como a semiótica, foi estruturada rigidamente, de modo mecânico, matemático (WARAT, 1995, p. 15):

Tanto a semiologia como a semiótica, apesar da diferença de enfoque e, em parte, do objeto temático, apresentam traços epistemológicos similares, pois ambas aderem a uma concepção de objetividade exterior à história e submetem-se aos imperativos da sistematicidade. Desta forma, ontologizam a razão, erigindo-a em um 'topos' metodológico.

Desse modo, do ponto de vista contextual, as pretensões científicas que subjazem tais teorias (semiótica e semiologia), podem ser circunscritas historicamente no âmbito da racionalidade moderna: cientificista, quantitativa, matemática, mecanicamente apreensível, pautada na busca da verdade racionalmente irrefutável; uma concepção de ciência que repercute fundamentalmente no papel atribuído à linguagem, bem como na compreensão das funções que esta pode ser capaz de desempenhar.

Considera-se que as funções da linguagem não se esgotam na análise dos signos. Para além de ser instrumento, a linguagem é, na verdade, condição de possibilidade. Significa dizer que a questãoproblema proposta neste estudo situa-se no pano de fundo dessas breves considerações prévias, que são fundamentais para o direcionamento do objeto teórico pretendido, uma vez que nele, por meio das contribuições da epistemologia da linguagem, insere-se a crítica ao discurso político-ideológico que sustenta a expressão "desenvolvimento sustentável".

Enfrentar esse desafio implica em aproximar-se de uma corrente filosófica que vislumbra a linguagem não como fenômeno natural do homem, isto é, detentora de um sentido que lhe é imanente, mas como decorrência de um contexto discursivo de permanente tensionamento dos poderes sociais.

Foucault (1999, p. 8-9) afirma, por isso, que a produção discursiva é socialmente "[...] controlada, selecionada, organizada e redistribuída por certo número de procedimentos que têm por função conjurar seus poderes e perigos, dominar seu acontecimento aleatório, esquivar sua pesada e temível materialidade".

Daí que não há como pensar a conjugação da expressão "desenvolvimento sustentável" como um simples acontecimento aleatório, mas, ao contrário, partindo-se de que o alcance da verdade advém de séries discursivas e descontínuas, deve-se lhe conceber como fruto de um período no qual o capitalismo passou a sofrer alguma chance de questionamento, vendo-se na contingência de tramar as condições de sua própria sobrevivência.

\section{A linguagem como discurso político-ideológico}

Uma vez apresentada a transição epistêmica da linguagem, de um caráter científico axiomático para sua compreensão como fenômeno dinâmico e social, dotado de significação persuasiva e que, permanentemente, é alimentada a partir do influxo de somatórios infinitos de manifestações de poder, importa desenvolver melhor tais ideias.

Para tanto, primeiramente propõe-se uma abordagem acerca do caráter objetivo da linguagem e dos seus eixos componentes: sintaxe, semântica e pragmática, seguindo-se de uma problematização em torno da verdade a partir das contribuições discursivas de Michel Foucault. 


\subsection{Da semântica e pragmática discursiva}

A pragmática discursiva consiste em um dos elementos que compõem a análise do positivismo lógico da linguagem. Assim, a teoria geral dos signos e dos sistemas de comunicação pressupõe a análise do signo a partir de três eixos: a sintaxe, a semântica e a pragmática.

O primeiro corresponde à relação dos signos entre si, ou seja, ao modo de construção de toda a linguagem. O segundo se propõe a relacionar os signos e os objetos a que fazem referência, localizando aí o problema da busca da verdade.

Nesse ponto, e acerca do conteúdo semântico das expressões, Warat (1995, p. 41) afirma que "[...] um enunciado não será semanticamente significativo se não for empiricamente verificável". É, pois, por meio da relação semântica que se analisa a coerência entre o discurso e o campo objetivo sobre o qual ele incide.

A busca da verdade consiste, nesse sentido, na análise, ou relação, entre os enunciados discursivos e sua concordância, ou correspondência, com o estado de coisas a eles subjacente. No caso da expressão "desenvolvimento sustentável", consiste em aferir se o conteúdo semântico nele traduzido corresponde à realidade objetiva de sua utilização.

Finalmente, o terceiro eixo que compõe a análise da teoria dos signos perfaz a pragmática, é dizer, dedica-se ao estudo da relação dos signos e de seus usuários. Eis aqui algo de especial interesse para a análise da expressão "desenvolvimento sustentável", pois, segundo Warat (1995, p. 46), é possível compreender novos significados, ou conteúdos semânticos, de acordo com o modo com o qual a expressão é utilizada pelos usuários, dado que o seu emprego pode provocar alterações na sua estrutura conceitual. Em suas palavras:

\footnotetext{
A teoria dos modos de significar levanta a questão de um deslocamento significativo em razão do uso concreto de um conceito ou expressão. [...] existiria uma significação independente dos contextos de uso (significação de base) que, quando empregada, tem sua significação alterada. Quando uma palavra é utilizada na comunicação, os destinatários captam um núcleo de significação no qual o contexto de uso não gravita; no entanto, o contexto provoca forçosamente um deslocamento significativo dessa compreensão para-contextual. Assim, por exemplo, se um emissor nos diz 'Lá fora está chovendo', entendemos, para-contextualmente, que nos está fornecendo uma informação sobre o tempo. Mas, no contexto, isto poderá ser dito por uma mãe para ordenar a seu filho que não saia à rua. Esta intenção diretiva é um complemento da significação que redefine a estrutura conceitual. (WARAT, 1995, p. 46).
}

O modo de significar de qualquer palavra pressupõe, pois, a análise de seu significado de base e de seu significado contextual, correspondendo, o primeiro, ao sentido congelado das palavras e, o segundo, ao efeito de sentido derivado dos processos efetivos da comunicação social.

Uma vez assentado os dois conteúdos de sentidos (significado de base e significado contextual, ou significado semântico e significado pragmático), é possível extrair da expressão "desenvolvimento sustentável" uma acepção relacionada ao significado congelado das palavras que nela se reúnem, mas também, e de modo mais relevante, outra que denota o que a expressão quer falar, tanto no seu ato de pronúncia quanto no de permanecer calado. Portanto, os sentidos provenientes em torno do que se fala e do que se deixa de falar por meio dela.

É a partir do que está por trás da expressão "desenvolvimento sustentável", ou seja, não do que ela apresenta como significado de base, mas, muito mais pela mensagem por ela traduzida, da visão e concepção de mundo que a orienta, que se poderá compreender o conteúdo político-ideológico nela contido. 


\subsection{A linguagem como produção discursiva enunciadora da verdade: contribuições de Michel Foucault}

Chauí (1999, p. 94), discorrendo sobre a verdade, constata que seu conceito é proveniente de um arcabouço de crenças e experiências pessoais, daí porque podem ser múltiplas as lentes que façam supor o seu alcance: verdades dogmáticas, religiosas, ou científicas. Identifica também que a busca da verdade em determinadas culturas assume condições diferentes de outras.

A autora registra, ao longo da história, três concepções distintas de verdade: a verdade por evidência, proveniente da experiência entre o sujeito e a coisa, através da qual sua significação, ou seu fenômeno, é consequência do ser-perceber (aletheia); a verdade por correspondência, oriunda do que seja afirmado acerca da coisa, consequência do dizer-falar (veritas); e, finalmente, a verdade por consenso, afirmada entre os participantes, baseada no crer-confiar (emunah) (CHAUÍ, 1999, p. 99-101).

Tais concepções estão intimamente relacionadas ao modo de reprodução da verdade e à forma como elas assumiram e assumem determinadas condições discursivas, sendo, em grande medida, fruto de um suporte institucional, reforçado e reconduzido por um conjunto de práticas, das quais se destaca a forma de aplicação do saber, ou de como ele é "valorizado, distribuído, repartido e atribuído" (FOUCAULT, 1974, p. 17).

Nesse viés, Warat está atento ao fato de que as linguagens não oferecem consequências apenas em relação às informações transmitidas, senão também acarretam "[...] ressonâncias significativas e normalizadoras de práticas sociais" (WARAT, 1995, p. 15), do que resulta que o impacto, ou pressão, dos discursos institucionais não produzem consequências exclusivas sobre a própria instituição, mas, ao contrário, apresentam-se como coerções em relação a outros discursos sociais. Sob essa ótica,

\footnotetext{
Retornando o tema do emprego estratégico dos conceitos, podemos dizer que a separação dos conceitos de suas teorias produtoras, permite a constituição de um sistema de verdades, o qual não está vinculado a conteúdos, mas sim, a procedimentos legitimadores, determinantes para o consenso social. Este consenso provém de um processo de conotações institucionais, que substituem a esfera do sentido conceitual por uma ordem de evocações controladas, ou seja, estereotipadas. Funda-se, por conseguinte um processo de apropriação institucional dos conceitos, cuidadosamente elaborado, para exercitar o poder dos significados. (WARAT, 1982, p. 55).
}

Não é possível, por isso, pensar a linguagem somente a partir do sistema no qual ela está inserida, mas também através da produção social de sentidos que dela parte e que nela é alimentada, correspondente ao seu significado social, para além do significado institucional. Assim, ainda que a vontade tenha como seu objeto a busca da verdade, ela nem por isso coincide com o "discurso verdadeiro", pois o que está por trás deste último são o desejo e o poder.

Foucault, na obra "A palavra e as coisas", afirma que o poder age sobre o exterior, sobre a ciência, e isso por si só pode alicerçar a verdade. Nessa linha, os "acontecimentos" só assumem essa condição a partir do momento em que se traduzam como espaços de transferência, produção e eliminação do próprio poder, e consequentemente alimentem a produção discursiva. Em conclusão, a verdade se apresenta como tensionamento entre as forças discursivas, que, por sua vez, são oriundas de espaços de poder.

A elucidação em torno da verdade, portanto, está bastante relacionada ao modo como os discursos operam. Nessa perspectiva, Foucault demonstra, em um de seus eixos metodológicos, que o discurso deve ser analisado "[...] não mais simplesmente sob seu aspecto linguístico, mas, de certa forma, como jogos ('games'), jogos estratégicos, de ação e de reação, de pergunta e de resposta, de dominação e de esquiva, como também de luta." (FOUCAULT, 1974, p. 6). O discurso é mais que a formalidade da linguística, antes consiste numa "luta estratégica e política".

Isso implica na constatação de que o conhecimento decorre de técnicas variáveis que possibilitam a elaboração de discursos que serão considerados verdadeiros, em maior e menor grau, uma vez que, a exemplo da credibilidade do enunciador, o "discurso verdadeiro" é capaz de assumir distintas proporções. 
A pertinência da crítica e das reflexões desenvolvidas pelo autor revela-se na aplicabilidade de sua teoria à contemporaneidade, sendo perceptível, sobretudo, pela atualidade de suas proposições, em especial aquelas relativas à construção de um discurso verdadeiro.

Já em função disso, Foucault (1999, p. 7) sinaliza que se o discurso carrega algum poder, é aquele que se lhe empresta, questionando onde se pode localizar o seu perigo. Na obra A ordem do discurso, o autor revela um embate entre o desejo dos indivíduos que não querem se circunscrever na ordem do discurso e a ironia institucional que assegura que "[...] o discurso está na ordem das leis" (FOUCAULT, 1999, p. 7) e, por isso, identifica uma inquietação que consiste, basicamente, na suposição de estratégias, lutas, perigos e poderes que envolvem a enunciação do discurso.

$\mathrm{Na}$ sociedade moderna, o discurso, longe de se apresentar livre, é marcado por procedimentos de exclusão ou interdição, separação ou rejeição, e falsidade ou verdade, sendo possível notá-los em relação aos discursos políticos (haja vista sua relação em torno do poder) (FOUCAULT, 1999, p. 9), ou aos discursos dos loucos, mas também através do silêncio que, em si mesmo, corresponde a uma forma eloquente de manutenção das coisas.

Nesse sentido, afirma-se que os discursos enunciados, sobretudo aqueles que possuem uma configuração institucional, encontram-se entrelaçados por relações de poder que muitas vezes não são perceptíveis, sendo capazes de compor um arquitetado "sistema de exclusão" identificável, para Foucault (1999), basicamente por três procedimentos: 1) a interdição da palavra, 2) a segregação da loucura, 3) a vontade de verdade.

Por razões metodológicas, tendo em vista a pertinência desta delimitação teórica para o avanço das reflexões pretendidas, optar-se-á por dar enfoque aos procedimentos de "interdição da palavra" e de "vontade de verdade".

A primeira consiste na impossibilidade de dizer. Uma restrição à fala que revela a relação de interpenetração entre os poderes e os discursos que dela emergem. Nessa perspectiva, considera-se o discurso não apenas como uma decorrência de um processo de dominação, mas como "[...] aquilo pelo que se luta, o poder do qual nos queremos apoderar" (FOUCAULT, 1999, p. 10).

Não seria absurdo assegurar que todos querem e, em alguma medida, exercem esse poder, ainda que o poder do discurso, manifesto pela interdição da palavra, assuma proporções mais cáusticas e incalculáveis em determinados âmbitos. Não há como desconsiderar o relevante papel da linguagem, determinadora, agendadora de sentido e significado e, de modo algum, ingênua.

Assim, quando o capitalismo parte de fatos, ou dados simplesmente postos, a exemplo da propriedade privada, do capital, da divisão do trabalho, do modelo de produção e desenvolvimento, dentre outros, isso acontece porque toda linguagem é dotada de intencionalidade e, mesmo quando silencia, não o faz sem razão de ser. Interdita com o fim de afirmar sub-repticiamente o modelo posto.

Dessa maneira, a ordem do discurso contribui para que cerceamentos sejam (im)postos e formas, jurídicas e não jurídicas, de violência se instaurem de um modo plural: a violência simbólica da mídia; a "violência do "colonialismo invisível" (GALEANO, 2012) exercido pelos governantes; a violência normatizada por leis que, direta ou indiretamente, contribue para o aprofundamento das desigualdades; e a violência invisível do mercado, naturalizada através da subordinação da proteção ambiental aos interesses econômicos.

Não é somente por esse jogo estratégico do inaudito, contudo, que o discurso pode ser analisado. Também o procedimento da "vontade de verdade" é capaz de, vestindo uma roupagem institucional, exercer sobre outros discursos uma coerção (FOUCAULT, 1999, p. 18). A "vontade de verdade" opera como um legitimador das verdades postas socialmente por saberes da ciência, da pedagogia, de laboratórios, do Direito, etc.. Logo, por meio das práticas e dos saberes aplicados, valorizados, repartidos e, de certo modo, atribuídos (FOUCAULT, 1999, p. 17). 
Em todo caso, a dinâmica da vida é capaz de referenciar diferentes nichos, ou focos, do poder por meio dos quais a "vontade de verdade" se manifesta. É dizer: sendo possível associar, na sociedade de classes, o discurso de "vontade de verdade" à classe dominante, especialmente corporificada na burguesia, talvez ele assuma atualmente espaços mais pulverizados, e ao mesmo tempo desterritorializados, como parece comprovar o discurso simbólico do mercado especulativo, que tão intensamente ditas relações de poder na sociedade globalizada neoliberal.

Isso guarda particular interesse na análise da construção da expressão "desenvolvimento sustentável", na medida em que é ela fruto de um jogo estratégico envolvendo Estados, mercado e sociedade, sem que isso possa significar uma análise restrita aos aspectos econômicos, ou representar a subordinação do poder a tais aspectos, senão também enquanto manifestações de poder.

Trata-se de como a "teoria das riquezas e da produção" (FOUCAULT, 1999, p. 18) vem sendo construída à luz de práticas econômicas assumidas como dogmas, sem que a questão se restrinja somente a isso, embora possa ter nela grandes repercussões. Questiona-se, portanto, o que está por trás do discurso que se pretende e se apresenta como verdadeiro na expressão "desenvolvimento sustentável", destinado a operar a permanência do capitalismo a partir de sua reconstrução.

Daí Foucault (1999) levanta outro ponto: "[...] as grandes mutações científicas podem talvez ser lidas, às vezes, como consequências de uma descoberta, mas podem também ser lidas como a aparição de novas formas na vontade de verdade", o que sugerem dúvidas sobre o grau de confiabilidade atribuído a determinadas instituições responsáveis por estabelecer regramentos à vida coletiva. Conforme esclarece Bauman (1998, p. 143),

A noção de verdade pertence à retórica do poder. [...]A disputa acerca da veracidade ou falsidade de determinadas crenças é sempre simultaneamente o debate acerca do direito de alguns de falar com a autoridade que alguns outros deveriam obedecer, a disputa é acerca do estabelecimento ou reafirmação das relações de superioridade e inferioridade, de dominação e submissão, entre os detentores de crenças.

Para além dos procedimentos exteriores de controle discursivo abordados ("interdição da palavra" e "vontade de verdade"), Foucault reconhece também estratégias interiores que promovem o seu controle a partir de "classificações", "ordenações" e "distribuição" em acontecimentos e acasos, além de "condições de seu funcionamento" (FOUCAULT, 1999, p. 21).

Elenca o autor, entre os mecanismos de controle interno, o "comentário" por meio do qual se identificam narrativas que se contam, repetem-se e se fazem esvaziar; o "autor", entendido como um princípio de agrupamento do discurso, como "[...] origem de suas significações e foco de sua coerência"; e, finalmente, as "disciplinas" que, opondo-se aos princípios do "autor" e do "comentário", possibilitam a proposição de novos enunciados mediante o preenchimento de exigências complexas. (FOUCAULT, 1999, p. 24-30).

Finalmente, as "condições de funcionamento" vão assegurar que nem todos tenham acesso ao discurso. Essas condições guardam relação com o ritual por meio do qual o discurso deve acontecer, ou seja, somam uma série de circunstâncias, de signos e de gestos que asseguram aos sujeitos "[...] propriedades singulares e papéis preestabelecidos" (FOUCAULT, 1999, p. 37-39).

Os rituais e os conteúdos discursivos, então, passam a orientar as "doutrinas" antes conhecidas como "sociedades de discursos", cujas funções orientam-se precipuamente à sua conservação, produção, manutenção e circulação em espaços fechados (FOUCAULT, 1999, p. 39-41). O pressuposto das doutrinas e consequentemente das ideias-base que as orientam é o reconhecimento recíproco entre os sujeitos dos processos discursivos formulados, ou seja, qualquer doutrina conta necessariamente com um conjunto de condições que permitem sua permanência e reprodução, sendo desde logo cerceadas as possibilidades em seu acesso. 
Portanto, não há espaço para ingenuidade, sendo possível que várias filosofias e doutrinas sejam fomentadas ao tempo em que servem à manutenção das coisas postas, dos sistemas existentes e/ou dos desejos dos detentores do poder sob a promessa da verdade, mas possivelmente distantes dela. Parece ser assim porque, afinal, os discursos se orientam pelas coisas mesmas e pelos acontecimentos manifestados, ocultando, segundo Foucault (1999, p. 49), "[...] o segredo de sua própria essência".

Pretende-se, pois, realizar uma análise contra discursiva, ou seja, uma verificação da ação de retorno das significações politicamente elaboradas à sociedade que, a partir de seus condicionamentos, elegem alguns discursos a partir dos quais soam como estratégias normalizadoras e disciplinadoras dos indivíduos e instituições.

Com efeito, a análise da expressão "desenvolvimento sustentável" estabelece um contínuo e permanente diálogo com a realidade por meio do qual sinaliza e alimenta, social e institucionalmente, a subordinação da proteção ambiental aos interesses mercadológicos, isto é, lembrando, a todo o momento, que a proteção ambiental encontra limites claros e precisos estabelecidos pelas perdas e ganhos do capital. Mas, isso, ver-se-á logo em seguida.

\section{O discurso político-ideológico do "desenvolvimento sustentável": subordinação da proteção ambiental ao desenvolvimento econômico}

A abordagem feita até o momento, pautando-se no referencial teórico adotado, considerou que a linguagem assume um caráter agendador e codificador dos discursos que permeiam o corpo social, e, nesse sentido, tem a potencialidade de excluir, limitar, propagar, condicionar ou fomentar os processos discursivos.

Como tal, a expressão "desenvolvimento sustentável" faz encobrir o que apenas por detrás dela seria revelado, ou seja, supõe dados e fatos como desenvolvimento, mercado, exploração da natureza, relacionando-os às condições de possibilidades de sobrevivência do próprio homem. Significa dizer que, pondo-se em destaque a necessária proteção ambiental, naturaliza-se o sistema exploratório como uma dicotomia, afirmando uma relação concorrencial entre o homem e a natureza, em cujo movimento humanista essa ideia seria descabida.

Ribeiro e Campos (2011, p. 648) assinalam o equívoco da expressão "desenvolvimento sustentável" argumentando que o conteúdo semântico do signo desenvolvimento já pressuporia a ideia de crescimento sem prejuízo, sem qualquer tipo de degradação ao meio ambiente. É de se supor, contudo, que os autores estariam corretos não fosse a distinção já estabelecida em torno do significado de base e do significado contextual. Daí que, se, a partir das lentes do significado de base, é possível afirmar que na própria palavra desenvolvimento estivesse contida a compreensão em torno da inexistência de prejuízos ambientais, não se poderia dizer o mesmo quando a leitura considera o contexto no qual o signo é inserido e utilizado.

Também seria possível sustentar que, do ponto de vista normativo, vigora uma igualdade no nível de proteção conferido pela Carta Constitucional à proteção ambiental e à atividade econômica. Nesse sentido, ao tempo em que a norma do art. 225, caput, assegura que "todos têm direito ao meio ambiente ecologicamente equilibrado, bem de uso comum do povo e essencial à sadia qualidade de vida, impondose ao Poder Público e à coletividade o dever de defendê-lo e preservá-lo para as presentes e futuras gerações", (BRASIL, 1988) também o art. 170 prevê que "a ordem econômica, fundada na livre iniciativa, tem por fim assegurar a todos existência digna, conforme os ditames da justiça social” (BRASIL, 1988), determinando a observância ao princípio da defesa do meio ambiente, inclusive mediante tratamento diferenciado conforme o impacto ambiental dos produtos e serviços, e de seus processos de elaboração e prestação.

Se no plano de um significado de base a expressão "desenvolvimento sustentável" não suporia maiores críticas, senão aquela que apontaria para um caráter supérfluo do signo sustentável, e se, no âmbito normativo, reconhece-se igual base de proteção a orientar a atividade econômica e a defesa 
do meio ambiente, de que forma se pode apontar o comprometimento da expressão "desenvolvimento sustentável" com um determinado discurso político-ideológico?

Por muito tempo, o discurso ideológico norteou a teoria da verdade, tendo reservado aos ideólogos um papel central na orientação e condução da sociedade, especialmente em relação à ignorância e a educação errônea, conforme noticia Bauman (1999, p. 116). Isso tudo pautou a busca pela racionalidade nas ciências e no mundo em geral. Mesmo quando a ideologia, em um segundo momento, passou do domínio do conhecimento ao domínio das crenças, sua compreensão se colocava arrogantemente contra aquelas tidas como desautorizadas pela razão. Recentemente, contudo, o conceito de ideologia passou a ser o de orientar (BAUMAN, 2000, p.123):

[...] molduras cognitivas que permitem encaixar vários fragmentos da experiência humana num desenho reconhecível e que faz sentido. As molduras são condições de conhecimento, mas não constituem elas mesmas partes dele; raramente, se é que alguma vez, são objeto de reflexão e formulação ou recebem um olhar de destaque 'de fora'. [...] Pela mesma razão, preservam a percepção padronizada e estruturada da realidade vivida em meio à velocidade crescente da informação, que ameaça explodir todas as estruturas e aniquilar todos os significados.

Trata-se de uma visão positiva da ideologia que renuncia qualquer pretensão de impor uma visão universal de mundo. Antes, tem como objetivo a compreensão em torno das diversas visões, a partir de sua diferenciação e diversificação conceitual. Há um claro rompimento com a visão kantiana de transcendentalidade, que vê o mundo a partir um imperativo categórico universal (BAUMAN, 1999, p. 124). Reconhece-se, pois, uma mudança de rota no conceito que orienta uma nova compreensão da ideologia, não mais limitada a ideias genéricas, aparentemente situadas no plano da racionalidade, como as relativas ao espaço, tempo, e causalidade, que sempre formataram as visões dos fenômenos.

O grande problema da expressão "desenvolvimento sustentável" é que ela permanece atrelada a uma visão de mundo única, que desconsidera as múltiplas formas de ser e de viver, e isso não é por acaso, mas pela discrepância entre globalização e localização, política e poder. Fundamentalmente, assiste-se a uma separação entre poder e política, pois suas condições de funcionamento orientam-se por critérios diametralmente opostos. Nesse viés, enquanto a política permanece sendo executada em bases físicas territorialmente bem localizadas, o capital passa a fluir pelo ciberespaço, abolindo qualquer vinculação espacial.

Mas, afinal, qual a repercussão dessa globalização engendrada pelo capital e compreendida na progressiva separação entre poder e política, e a ideia de desenvolvimento sustentável? Estando a ideia de poder atrelada ao capital, ele sinaliza uma monocultura em relação às formas de ser e de viver que despreza as outras ecologias a que faz menção Boaventura de Souza Santos (2010), e que passa a orientar o significado contextual da expressão "desenvolvimento sustentável" a partir do conceito hegemônico que Ihe é empregado.

Em "Globalização: as consequências humanas", sinaliza Harvey (apud BAUMAN, 1999, p. 63) a superação dos limites territoriais e espaciais da economia:

A economia - o capital, que significa dinheiro e outros recursos necessários para fazer as coisas, para fazer mais dinheiro e mais coisas - move-se rápido; rápido o bastante para se manter permanentemente um passo adiante de qualquer Estado (territorial, como sempre) que possa tentar conter e redirecionar suas viagens.

A atribuição do significado contextual que é ordinariamente empregado à expressão "desenvolvimento sustentável" tem como base de sua sustentação a circunstância de que seu nascimento está atrelado a um projeto internacional de construção de bases científicas hegemônicas que, por isso mesmo, negam existência, ou valor, a diferentes culturas e outras formas de assimilação do tempo e produção, além de naturalizar conceitos necessários à sua manutenção. 
Acerca das razões pelas quais ordinariamente se percebe a realidade a partir das lentes hegemônicas da cultura ocidental, Santos (2010, p. 97) aponta a contribuição de Hegel e de sua dialética, ou seja, a forma binária de assimilação da realidade a partir da razão metonímica, dualista e reducionista que orienta a sua compreensão e transforma interesses hegemônicos em conhecimentos verdadeiros, eliminando ou reduzindo outras formas que não obedecem a sua lógica.

A obsessão hegeliana pela ideia de totalidade e pela compreensão da realidade por meio da razão metonímica sinaliza a primazia do todo em relação às partes, tornando invisíveis as características peculiares que identificam as condições particulares, ou compõem as partes envolvidas.

Santos (2010, p. 98) afirma que é em função dessa primazia da razão metonímica que as dicotomias favorecem uma hierarquização: "cultura científica/cultura literária; conhecimento científico/conhecimento tradicional; homem/mulher; civilizado/primitivo; branco/negro", etc.

No caso da expressão "desenvolvimento sustentável" e do significado contextual que ela sinaliza, pode-se afirmar a primazia de um modelo de desenvolvimento que se orienta precipuamente pela valorização do capital, apresentando-se a proteção ambiental como apêndice, ou questão hierarquicamente de menor relevância social, e isso tem uma razão de ser.

O modo de organização da sociedade e as formas estruturantes pelas quais o capital foi assumindo a condição de instrumento hegemônico do poder apontam para uma permanente subordinação de qualquer outro referencial, mesmo a proteção ambiental. Isso, por óbvio, foi possível graças aos discursos que orientaram e permanecem orientando as bases de sustentação do modo de produção capitalista, sinalizando promessas de qualidade de vida, minimização da pobreza e afirmação dos direitos e garantias fundamentais. Bauman (1999, p. 67) traz argumento que auxilia essa compreensão:

\begin{abstract}
Os conceitos de 'civilização', 'desenvolvimento', 'convergência' e 'consenso' e muitos outros termos chaves do pensamento moderno inicial e clássico, a ideia de 'universalização' transmitia a esperança, a intenção e a determinação de se produzir a ordem; além do que os outros termos afins assinalavam, ela indicava uma ordem universal, a produção da ordem numa escala universal, verdadeiramente global. Como os outros conceitos, a ideia de universalização foi cunha com a maré montante dos recursos das potências modernas e das ambições intelectuais modernas. Toda a família de conceitos anunciava em uníssono a vontade de tornar o mundo diferente e melhor do que fora e de expandir a mudança e a melhoria em escala global, à dimensão da espécie. Além disso, declarava a intenção de tornar semelhantes as condições de vida de todos, em toda parte, e, portanto, as oportunidades de vida para todo mundo; talvez mesmo torna-las iguais.
\end{abstract}

Tais discursos tornados universais fixam-se, fundamentalmente, em cinco modos de produção de não existência, conforme critério proposto por Santos (2010, p. 104): a monocultura do saber e do rigor do saber; a monocultura do tempo linear; a lógica de classificação social; a monocultura dos critérios de produtividade capitalista e a lógica da escala dominante. Para o recorte proposto neste estudo, destacase a monocultura dos critérios de produção capitalista, que sinaliza que o crescimento econômico é algo racionalmente justificado e que tende a inferiorizar o que se mostre improdutivo, seja desqualificando-o como preguiçoso, seja reportando à natureza como estéril.

Reconhecendo essa estrutura de assimilação da realidade, a expressão "desenvolvimento sustentável" é contextualizada a partir de uma lógica globalizada que orienta, para além de seus significados de base, também significados contextuais que informam a sua compreensão. $O$ apelo à expressão, dotada de alto grau de generalização, não é por acaso. Fala-se tudo e nada ao mesmo tempo.

Olivo e Misoczky (2015, p. 2), acerca dessa conveniente opacidade da generalização da expressão, afirmam que ela se torna mais importante quando se considera a premissa de que

[...] os processos históricos, refletidos nos discursos políticos, bem como em outros, são revestidos de uma espécie de 'opacidade linguística', dificultando perceber claramente os esquemas enrustidamente classificatórios - regras, estruturas, ideologias- que se produzem em cada campo específico. 
Não seria isso senão a aplicação das estratégias discursivas a que faz menção Foucault? Seja fazendo incidir mecanismos externos, a exemplo da "vontade de verdade", seja por meio dos procedimentos internos de "classificações", "autoria", "ordenação", ou ainda "condições de funcionamento" de produções discursivas?

Paralelamente, na medida em que o discurso dogmatiza o pensar, limitando-o àquilo que a expressão "desenvolvimento sustentável" impõe como seu pressuposto, também opera segundo o mecanismo da "interdição da palavra", censurando, no plano que antecede a externalização, as possibilidades de confronto ao modelo de desenvolvimento vigente.

Percebe-se, pois, que a palavra "desenvolvimento" carrega em si uma conotação universalista, única e hegemônica que historicamente é comprovada, e que mais contribuiu para o avanço das pretensões de expansão do capitalismo e do processo de globalização do que para os processos de emancipação social, valorização cultural e proteção ambiental almejados. É dizer: esse universalismo contribui para a solidificação dos ideais que norteiam as culturas hegemônicas ao revés de fomentar os processos de valorização da diferença, do pluralismo social e da proteção ambiental.

A análise das justificativas apresentadas quando do nascimento da expressão durante a elaboração do Relatório da Comissão Mundial sobre Meio Ambiente e Desenvolvimento Sustentável, também conhecido como Relatório de Brundtland, marca a constituição do campo internacional do desenvolvimento sustentável (CIDS) (CMMAD, 1988, p. 38 e 346) e é bem esclarecedora:

Hoje temos de nos preocupar também com o modo como a deterioração ambiental pode impedir ou reverter o desenvolvimento econômico. [...] O necessário, agora, é uma nova era de crescimento econômico, um crescimento convincente e ao mesmo tempo duradouro do ponto de vista social e ambiental [...]. Chegou o momento de romper com os padrões do passado [...] é preciso buscar segurança através de mudança. A Comissão aponta várias providências que podem ser tomadas para reduzir os riscos ambientais à sobrevivência e indicar rumos sustentáveis para o futuro desenvolvimento. Sem essa nova orientação das atitudes e prioridades, pouco se conseguirá.

Veja-se que a preocupação consiste em assegurar que a deterioração não impeça ou reverta o desenvolvimento econômico, sendo a preocupação ambiental requerida, tão somente, na exata medida em que contribua para os avanços do mercado. Olivo e Misoczky $(2015$, p. 01) fazem coro à ideia ao afirmarem que: "Percebe-se, novamente, o que é disputado neste campo: o capital ambiental, não como um bem da humanidade, mas como um meio para viabilizar o desenvolvimento econômico".

Analisando ainda o trecho no qual o relatório (CMMAD, 1988, p.14, grifo nosso) aponta para a necessidade de:

[...] reexaminar as questões críticas relativas ao meio ambiente e desenvolvimento, e formular propostas realísticas para abordá-las; propor novas formas de cooperação internacional nesse campo, de modo a orientar políticas e ações no sentido de mudanças necessárias; e dar aos indivíduos, organizações voluntárias, empresas, institutos e governos uma compreensão maior desses problemas, incentivando-os a uma atuação mais firme.

Olivo e Misoczky (2015, p. 5) destacam a natureza eminentemente simbólica utilizada no discurso quando se utiliza de verbos como "reexaminar", "orientar", "formular". Para evidenciar a natureza retórica do discurso, formulam indagações que a isso remete, a exemplo de "Qual o sentido de propostas realísticas e a quem compete a sua formulação? Quem está legitimado para orientar as políticas? Que mudanças necessárias são estas? Quem está incluído na "cooperação internacional e qual seus condicionantes?".

Ora, a ausência de respostas básicas que possam viabilizar e objetivar minimamente em que consiste o "desenvolvimento sustentável" torna a terminologia apenas uma expressão socialmente reclamada, uma espécie de chancela internacional a viabilizar o mesmo padrão de produção e consumo que ora se vem estabelecendo. No mais, representam a manutenção das monoculturas sinalizadas, em prejuízo da riqueza das experiências possíveis, e corroboram a utilização da linguagem como estratégia política 
normalizadora e disciplinadora dos indivíduos, das instituições e, consequentemente, dos discursos e significações por eles conduzidos.

\section{Conclusão}

O reconhecimento da linguagem como fenômeno natural do homem, detentor de um sentido que Ihe seja imanente, é demasiadamente pobre e somente pode alcançar sua exata medida se inserido num contexto discursivo que lhe atribua significado, situando-o em uma perspectiva de permanente tensionamento dos poderes sociais.

Em Foucault, os "jogos estratégicos" de ação e de reação, que perscrutam os fatos, sinalizam para as possibilidades discursivas de dominação - inclusive, política - decorrente de técnicas variáveis, seja mediante a "interdição da palavra", seja em virtude da "vontade de verdade", que viabilizam a elaboração de discursos que serão, em maior ou menor grau, considerados verdadeiros.

Nessa toada, o que está por trás da expressão "desenvolvimento sustentável" não o que ela apresenta como significado de base, mas a mensagem por ela traduzida. A visão e concepção de mundo que a orienta deve nortear a compreensão de seu conteúdo político-ideológico.

Essa compreensão remete ao fato de que a expressão foi cunhada de modo atrelado a uma construção de bases científicas hegemônicas que, por isso mesmo, nega existência e valor a diferentes culturas e a outras formas de assimilação da relação tempo e produção. Uma lógica binária que pretende homogeneizar a realidade a partir da razão metonímica, dualista e reducionista.

Nesse sentido, é possível perceber que a subordinação ambiental é sub-reptícia e orientada principalmente por interesses hegemônicos das sociedades ocidentais, destinados a manter as condições de sobrevivência do modo de produção capitalista.

É nesse contexto que a expressão "desenvolvimento sustentável", ainda que inicialmente cunhada como alternativa aos limites do crescimento econômico, serve antes à manutenção dos ideais de sobrevivência da ordem capitalista globalizada, estabelecendo um contínuo e permanente diálogo com a realidade por meio do qual sinaliza e alimenta, social e institucionalmente, a subordinação da proteção ambiental ao desenvolvimento econômico e lembrando, a todo o momento, que a proteção ambiental encontra limites claros e precisos, estabelecidos pelas perdas e ganhos do capital.

\section{Referências}

BARONI, Margaret. Ambiguidades e deficiências do conceito de desenvolvimento sustentável. Revista de Administração de Empresas, São Paulo, v. 32, n. 2, p. 14-24, abr./jun. 1992. Disponível em: <http:// www.scielo.br/pdf/rae/v32n2/a03v32n2.pdf>. Acesso em: 09 set. 2015.

BAUMAN, Zygmund. Globalização: as consequências da modernidade. Rio de Janeiro: Jorge Zahar, 1999.

BAUMAN, Zygmund. O mal-estar da pós-modernidade. Rio de Janeiro: Jorge Zahar, 1998. Disponível em: <http://www.grupodec.net.br/ebooks/ZygmuntBauman-Omal-estardapos-modernidade.velhojou.www. therebels.biz.pdf>. Acesso em: 10 set. 2015.

BAUMAN, Zygmund. Em busca da política. Rio de Janeiro: Jorge Zahar, 2000.

BRASIL. Constituição (1988). Constituição da República Federativa do Brasil. Senado: Brasília, DF, 1988. Disponível em: <http://www.planalto.gov.br/ccivil_03/Constitui cao/Constituicao.htm>. Acesso em: 24 jul. 2015.

BRÜSEKE, Franz Josef. Parte I: A economia da sustentabilidade: princípios: o problema do desenvolvimento sustentável. In: CAVALCANTI, Clóvis (Org.). Desenvolvimento e natureza: estudos para uma sociedade sustentável. Recife: Instituto de Pesquisas Sociais-Fundação Joaquim 
Nabuco (INPSO-FUNDAJ), 1994. Disponível em: <http://biblioteca.clacso.edu.ar/Brasil/dipes-fundaj/ uploads/201211290 23744/cavalcanti1.pdf\#page=15>. Acesso em: 25 set. 2015.

COMISSÃO MUNDIAL SOBRE MEIO AMBIENTE E DESENVOLVIMENTO (CMMAD). Nosso futuro comum. Tradução de Our common future. Rio de Janeiro: Fundação Getúlio Vargas, 1988.

FOUCAULT, Michel. A ordem do discurso. 5. ed. São Paulo: Edições Loyola, 1999.

FOUCAULT, Michel. A verdade e as formas jurídicas. Rio de Janeiro: PUC, 1974.

GALEANO, Eduardo. O livro dos abraços. 9. ed. Porto Alegre: L\&PM, 2002.

OLIVO, Vania Maria Fighera; MISOCZKY, Maria Ceci. As estratégias discursivas presentes na origem do referencial para o desenvolvimento sustentável: uma análise crítica do Relatório de Brundtland. Disponível em: <http://www.anpad.org.br/diversos/trabalhos/EnANPAD/enanpad_2003/ POP/2003_POP1757.pdf>. Acesso em: 09 set. 2015.

PETERS, Michael. Pós-estruturalismo e filosofia da diferença: uma introdução. Belo Horizonte: Autêntica, 2000.

WARAT, Luís Alberto. Saber crítico e senso comum teórico dos juristas. Revista Seqüência: Estudos Jurídicos e Políticos, Florianópolis, v. 3, n. 5, p. 48-57, 1982. Disponível em: <https://periodicos.ufsc.br/ index.php/sequencia/article/view/17121/15692>. Acesso em: 09 set. 2015.

WARAT, Luís Alberto. $\mathbf{O}$ direito e sua linguagem. 2. ed. Porto Alegre: Sergio Antonio Fabris Editor, 1995.

WITTGENSTEIN, Ludwig. Investigações filosóficas. São Paulo: Abril Cultural, 1979. (Coleção Os pensadores).

SANTOS, Boaventura de Souza. A gramática do tempo: para um nova cultura política. São Paulo: Cortez, 2010.

Recebido em: 09/08/2016.

Aprovado em: 11/05/2017. 